\title{
Discussion on Introducing Teaching Mode of "Limited Style Guidance" in Basic Courses of Fine Arts in High Normal Universities
}

\author{
Jun Zhu \\ College of Fine Arts \\ Huanggang Normal University \\ Huanggang, China
}

\author{
Shaozong $\mathrm{Hu}$ \\ College of Fine Arts \\ Huanggang Normal University \\ Huanggang, China
}

\begin{abstract}
This article discussed the organization pattern and teaching process of course contents of basic drawing courses in fine arts specialty at high normal university (teachers' education). We put forward: in the stage of professional basic teaching, adopt limited style, summarize linguistic elements with specific artistic pattern to facilitate teaching mode of modern class teaching. Teachers dominate this process. Teachers and students research together and jointly interpret the freedom of visual creation, and then students will not be at a loss when they meet too broad knowledge of fine arts history, especially colorful and complex styles related to technique language. It can make them learn several limited styles in particular period and then process from the one to the other step by step, and correspondingly establish evaluation standard that conforms to the process of limited style guidance.
\end{abstract}

Keywords-fine arts; basic course; guidance of limited style; thoughts on teaching

\section{INTRODUCTION}

\section{A. Raising Questions}

This article discussed the organization pattern and teaching process of course contents of basic drawing courses in fine arts specialty at high normal university.

According to current school system of higher education in our country, except for few specialties, the in-school time of an undergraduate student in fine arts specialty is four years in general, while the total class hours specified by teaching program of universities at all levels is between 2,600 and 2,900 hours. Except for basic courses of humanity and general knowledge, the total in-class hour of fine arts specialty is about 1,500 hours. This is the time duration of professional learning of an undergraduate student in fine arts specialty in schoolnamely "the length of college". The "length" of this school system is fixed and can be regarded as invariant. So, the number of courses opened by each specialty and course contents - namely "the width of course" - it changes with the change of different teaching ideas, different teaching objectives, different teaching modes as well as different evaluation standards. So it is a variable. It can be concluded that: under the circumstance of fixed time, if we think other factors that influence learning efficiency are consistent, the variable of course and content decide the depth of knowledge learned by students and width of knowledge mastered by them. Here we discuss: can we think under the circumstance of fixed time, the wider the course contents, the better it helps students' learning in specialty and accumulation of knowledge? The answer is obvious no. Therefore, on the basis of this understanding, this article tries to think on content setting of basic courses of fine arts specialty at high normal university (teachers' education) and teaching of fine arts knowledge.

We know that under the mode of class teaching system, the course teaching is carried out on the basis of existing knowledge system of specific subject. Therefore, the accumulation of human knowledge related to this subject, including thinking mode opposed to it and people's recognition for the cultural patterns contained by it, enters teaching materials in the choice of the times and becomes the premise and basis to pass wisdom and acquire knowledge. The existing knowledge is passed on from generation to generation in continuous recombination. New knowledge is also produced constantly. Meanwhile, the mind of people is also exercised in this process. In this sense, the process of accumulation, inheritance and acquisition of human knowledge are just like the construction process of bridge, belonging to "the process of progressive structure". The difference is that the construction of bridge belongs to one-dimensional structure from the first pier to the final pier, while the accumulation and creation of knowledge present the progressive course of multiple dimensions from the origin of knowledge.

The research of educational psychology thinks that the general mode of process of knowledge learning can be divided into five links:

Firstly, the learning of new knowledge begins from attention, which is similar to the fact that the growth of knowledge begins from question;

Secondly, through attention, students choose information materials related to the present learning tasks and concentrate the limited mental energy on corresponding activities. At the same time, the original knowledge related to new information and stored in long term memory is started; 
Thirdly, new information enters the working memory system. Students can find relationships among parts of new information;

Fourthly, the original knowledge in start state related to new information becomes related to new knowledge;

Finally, new knowledge enters the long term memory to be stored [1]. The learning of knowledge is a complicated process. The learning of different types of knowledge shows different structure types and they even cross and integrate with each other. However, through analysis of the above-mentioned five links of learning, we know clearly that the significance of original knowledge can not be neglected in the learning of new knowledge and it is an important link in the chain of learning. Original knowledge is the first pier of individual knowledge construction and also an important bridge that cannot be surpassed in mental maturity of individuals. On the basis of the above analysis, after considering and discussing the changes in the relationship between the length of college and the width of course, we put forward that teaching of basic courses in fine arts specialty, especially the teaching of sketch and color, should implement the teaching mode of "limited style guidance" - and aim at the learning of art language in basic training. The so-called teaching mode of "limited style guidance" of art language refers to a kind of teaching method that in a relatively stable teaching period, teachers of professional basic courses systematically research artistic style of similar painter groups in fine arts history and extract main contents of teaching and apply them to teaching practice of color and sketch. It is a process of teaching practice to comprehensively develop and design courses, teaching contents and teaching process. We know that there are many important painters in the history of art of painting. They provide a good deal of excellent artistic works and rich manifestation modes for late-comers and also develop changeable aesthetic taste. Meanwhile, they provide a large number of outstanding painting models for late-comers to learn and provide possibility for the development of art. However, there are two problems in using the existing resources in fine arts history to make someone finish the learning under certain teaching time and limited teaching contents:

Firstly, these artists in history are not teachers. They only teach painting in work room and mainly leave works for later generations. They are complete models of art instead of realizing teaching process of works. The artistic technique and realization process are hidden behind the works.

Secondly, style of works created by different artists in different periods and different cultural backgrounds in art history is colorful. The techniques of expression differ in thousands of ways. Sometimes they are even totally opposite to each other. The learning of art is a process with strong practicality. It needs learners to master corresponding art language and technique of expression related to it. Art becomes possible only in training of techniques, understanding of language and expression of feelings.

Therefore, to solve the above two problems, we can only deconstruct art language, aim at specific forms and styles, summarize knowledge factors of art language for the sake of teaching mode of modern class teaching method. Teachers dominate in this process. Teachers and students participate in the research together. In the learning process that is normalized and routinized, teachers and students jointly interpret the freedom of visual creation, thus students will not be at a loss when they face too broad knowledge of fine arts history, especially the colorful and complex style related to technique language. It can make them learn several limited styles in particular period and then process from the one to the other step by step.

\section{B. The Background of Raising Questions}

In 2003, Xi'an Academy of Fine Arts held "International Modern Sketch Art Exhibition". Representatives from more than ten colleges of fine arts in China, Australia and Britain took part in the exhibition and seminar. Mr. Pan Xiaodong in oil painting department of Xi'an Academy of Fine Arts puts forward the teaching mode that implements "limited style guidance" in sketch teaching. It's a pity that discussion on this meaningful teaching theory receives no attention and he doesn't do in-depth research on this problem. But this mode still has a positive significance and existing background in current basic teaching of professional fine arts in our country, especially the teaching of painting. The author bases on nearly two decades of professional teaching experience and brings the organization pattern of teaching content in basic course of painting in specialty of fine arts at high normal universities (teacher's education) for further discussion.

Through analysis we think the problem is put forward on the basis of the following backgrounds.

Firstly, the current publishing career is developed; painting materials of all kinds of styles are extremely easy to obtain; fine arts exhibition at all levels can be watched and downloaded randomly from the network without limitations of time and space; students are at a loss in all kinds of dazzling normal forms of artistic style;

Secondly, in western countries, schools have been brilliant and varied since the modern art; the patterns of postmodernist art is more colorful; the connotation of art suffers from huge impact time and time again. Therefore, the diversification and randomness related to artistic evaluation go against the training of students' feelings for art language.

\section{THE PRINCIPLE OF TEACHING MODE GUIDED BY} LIMITED STYLE: RULE OF ART LEARNING—FROM “TECHNIQUE" TO “PRINCIPLE"

We know that the current art practice is no longer the work that the master trains the apprentice. The class teaching system in colleges can recruit students on a large scale and realize large-scale class teaching. This mode makes the inheritance and creation of art thoroughly go out of manual workshop. Visual art style is sediment of historic culture. The techniques related to artistic creation and cultural factors contained in techniques enter teaching through the way of courses. Therefore, each specific course of art is the combination of techniques, art and knowledge. In the structure of teaching system in colleges, namely subject of fine arts, specialty of fine arts and specific courses, the course has its absoluteness. In comparison, the concept of specialty is the product under 
social division of labor and it is relative. Subject is the embodiment that social division of labor divides knowledge category. It is a process of continuous separation and recombination and relative as well. Therefore, among the above three, the course is the most important. The course is the core and supporting point related to this specialty. Learning specific courses well means that it is possible for learners to find new supporting point in the future life career. Different people choose different combinations of courses and will have different career choices. Therefore, universities at home and abroad generally favor the credit system. The secret is here. The course of fine arts can be divided into two categories: the first is the class of theory, which centers on word language. So far, word language is an important means for human to record, express, transmit and store knowledge. Mastering knowledge, expressing feelings and storing information through word language will always be the main cultural medium for human. For students in specialties related to fine arts, theories related to fine arts must be included in main courses of fine arts discipline. Secondly, the course of visual practice is technique itself. The learning of art is generally from "technique" to "principle". The system of technique is relatively closed, while theory embodies the flexibility of concept transition. The learning of them can supplement each other.

According to analysis of contemporary fine art education, it is found that no matter for easel painting or art design, putting aside the name of specific course, the course of technique contains a few key points: technique of form expression, grasp rule of visual form and sensibility for materials and medium of expression. The combination of the three points runs through the whole education process of fine arts techniques. It is substantive content in teaching of techniques.

As for individual students, the learning of these contents is just like the training of human language. The process of teaching and learning can be finished by a relatively uniform standard under the guidance of a relatively stable style in relatively centralized time. It is difficult to image that a person can develop speaking habits with strong ability of expression under random and diversified language environment. The creativity and freedom embodied in artistic spirit and art language are different from the rules of art learning. In other words, abiding by the rules of art learning does not hinder the free creative activities of art. Since the 1960s, in western countries, researches on psychology in art and principles of art history done by Gombrich, a scholar from Britain and Arneim, a scholar from America had systematically discussed the rules of visual arts learning and put forward the art inheritance mode that "the influence of painting on painting surpasses all other factors". This is the summary for art learning modes in ancient times and enlightenment for subsequent learners. Meanwhile, it profoundly expounds the importance of certain styles in the process of art learning.

Since modern and contemporary times, with continuous optimization of social technology conditions, art has penetrated in every aspect of social life. Art disciplines have gradually become important components in humanities. So to speak, just like philosophy, literature and history in humanities, the present art disciplines have complex and complete structural system of discipline and profound social and cultural significance. A person who contributes to the society must be thoughtful. For most people, the deepening of thought is not the result of pure rational thoughts, but promoted in a large number of practices related to concrete behaviors. This fact conforms to general principle of generating of human wisdom. Piaget, a western famous psychologist, thinks that the intellectual development of human promotes the form and development of their own thinking by using body actions as means of "motion and evolution". The specialty of fine arts has a prominent characteristic in humanities, namely, courses in this subject have very strong practicality. The best method to understand and grasp general rule of art is direct art practice. This process can be understood as: improve students' cognitive power in culture through creation of form; improve the judgment for culture through artistic appreciation; improve the grasp of social history through learning of art history and theory of art. The combination of the above three is the way from "technique" to "principle".

However, the grasp of "technique" is carried out under certain mode. The accumulation of visual experience and creation of visual form should be implemented in specific theme. Gombrich, a famous art historian in Britain says, "If there is no original system and the original hypothesis provided for us to verify or falsify, it is impossible for us to "understand" the countless vague stimulating signals given by surrounding environment [2]. Obviously, the acquisition of art experience and exercise of artistic technique are carried out in original system. Through doing research on the artistic creation process of western early masters of art represented by Rubens, Gombrich finds, "bridle-wise painters learn a good deal of schemas and rapidly draw the pattern of an animal, a flower or a house on the paper according to these schemas. It can be supporting points to reappear images in his memory. And then he gradually modifies this pattern until it becomes the thing that he wants to express [3]." The inheritance and creation of human knowledge are implemented on the existing basis. The inheritance and criticism are carried out in the objects set before under a reference system provided for us to criticize and modify. Only by doing this can we go to the next "pier" of knowledge. Wolfflin, the founder of theory of western artistic style, says when he talks about the observation and learning of art form, "as long as we do not know the form of observation, our observation for nature is an empty concept". The "form of observation" mentioned by him hits the nail on the head and points out the guiding significance of learning of art language, especially the early learning style-normal forms of certain artistic style on us. He also says, "The influence of painting on painting is much bigger than the influence of nature on painting." The change of style in art history is not to change natural scene-objects painted, but base on criticism and inheritance of inherent styles in art history [4]. The nature of art form is not the external object portrayed by it, but the embodiment of inner spirit of people who create the form. Therefore, visual form is the external and material embodiment of people's spirit. Just like the learning of human language, its inheritance needs to absorb people's knowledge and experience in this field and develops forward on a new level. Some people say the spirit of western art is critical. The social value of art is embodied in the criticism on culture and 
social thought. The inheritance of its art form and art language is also carried out in continuous criticism for traditional style.

Since the 1950s when colleges of fine arts were established, China has adopted the system of working room and discussed the conversion relation between the system of work room and teaching in colleges. This practical exploration follows: under the premise that the learning cycle of students in schools is fixed, the critical point to cultivate a talents with artistic creativity is that there should be relatively unified samples of style in particular period - namely the exploration on teaching practice guided by limited style, use this to open the door of art for individuals and open the road of artistic creation.

\section{INTRODUCING THE TEACHING MODE GUIDED BY LIMITED STYLE CAN COORDINATE THREE MAJOR CONTRADICTIONS}

In basic course teaching of the specialty of teachers' education in fine arts, implementing the teaching mode guided by limited style in the form of painting language can embody substantive characteristics of teachers' education and demands of the time. The research and exploration centered on teaching contents show the pertinence of professional training in elementary stage of development of teachers and highlight the definite substantive learning contents such as painting language and technique of expression as well as point out specific paths of obtaining techniques of artistic expression, and then solve three major contradictions that may appear in practical teaching of art.

Firstly, it effectively solves contradictions of school education on limitation of time and openness of present teaching materials. The guidance of limited style can form targeted learning contents;

Secondly, the demonstration of fine arts teaching makes contradictions appear between the teaching principle of "teaching students in accordance of their aptitude" and teachers' preference on unique style of art, so the guidance of certain style will form more learning resources;

Thirdly, it effectively solves the contradiction between increasingly open visual art concept and traditional learning style of fine arts;

Besides, the contradiction between "neutral principle" of class education form in schools and affective evaluation in artistic appreciation of painting is solved. So over a period of time, the learning of certain artistic form will form targeted communication for interactive activities between teaching and learning.

The research on this teaching mode aims at the characteristics of art teaching with strong practicality and intuition, discusses the reform of teaching contents under the background of diversified style of fine arts history and openness of contemporary art style. What's more, it embodies the experimental subject finished in the theme of teaching contents and in concrete teaching process of bilateral interaction between teachers and students. Therefore, it pays attention to the first post for the growth of practitioners of teachers' education of fine arts, sets the training scheme of individual ability to operational process, and establishes visual environment and exemplary resources for learning of art language technique as well as forms the system that combines lesson preparation of teachers, teaching process, students' practice and teaching evaluation.

\section{IMPLEMENTATION PROCESS OF TEACHING GUIDED BY LIMITED STYLE IN BASIC COURSES OF FINE ARTS}

Introducing teaching mode guided by limited style in basic teaching of fine arts will bring a false understanding: will contradiction generate between limitation of style of teaching models and openness, creativity of concept of artistic creation as well as diversification of art language?

The settlement of contradiction relies on scientific setting of teaching process and open teaching evaluation.

This research topic is purposed to systematically research painters group and style of works that adapt contemporary basic teaching of fine arts in fine arts history both in the east and the west through teachers, arranges teaching models that suit the basis of specialty of teachers' education of fine arts, in order to form teaching contents that conform to teaching program. Aiming at this teaching mode, it designs the following specific teaching steps:

Firstly, through the study on demands of the time of visual culture development, it analyzes mental mechanism of students' personal growth, puts forward the way of lesson preparation of sketch and color in basic courses of teachers' education specialty in fine arts at each stage, gives full play to the function of art studio and teaching and research office, and forms distinctive team.

Secondly, it make research on teaching requirements for sketch and color at different stages, selects models of technique language that has exemplary significance and reasonably compile the successive relationship between styles;

Thirdly, establish evaluation method that conforms to the teaching process guided by limited style. The observation point of evaluation can be thought from the following points of view:

Evaluate the representativeness of models selected on technique language;

Evaluate visual logic and cultural logic of models at each stage;

Evaluate the openness of works selected by models;

Evaluate degree that teachers master the "limitation" and "openness" of models at different learning stages;

Evaluate the degree of learning of students for particular styles at each stage and their abilities in achieving mastery through a comprehensive study of the subject.

Fourthly, the learning of fine arts history can strengthen students' mastery for history of artistic style, expand visual experience and make them combine the relative limitation of technique language learning with openness of artistic concept. In the learning of history of fine arts, it emphatically explains the inherent relationship of style of art history, makes the explanation of cultural history correspond to the explanation of 
schools and clues of artistic style and then distinguish key points of them.

Summing up the above analysis, we think that researching on the fact that implements guidance of limited style in basic course teaching of teachers' education specialty of fine arts refers to the research on course contents from the operational level. However, the nature of this research involves four links, namely, the lesson preparation of teachers, teaching content, teaching practice and teaching evaluation. Therefore, problems that need to be solved include:

Firstly, the link of lesson preparation of teachers: grasp the context of evolution of overall style of fine arts history and provide support for the preparation of artistic creation and teaching models;

Secondly, the link of students' practice: open corresponding catalogue of model pictures for students, arrange the environment of studio, provide knowledge background to make them understand formal characteristic of corresponding styles and schools of painting;

Thirdly, the link of teaching content: confirm relatively stable and similar groups of artistic style and works and broaden background knowledge on art history and appreciation level;

Fourthly, the link of evaluation: through the guidance of evaluation, realize four combinations in teaching: the combination between openness and definitive property of evaluation, the combination between creativity and inheritance, combination between the law of commonness and individuality of art learning, as well as the combination between basic learning and creative practice.

It should be said that the mode guided by limited style has very high promotional value in professional teaching of fine arts discipline. The achievement of teaching research can be expanded to other major fields: traditional Chinese painting, oil painting and watercolor and penetrated in the teaching of many specialties of art and design.

\section{REFERENCES}

[1] Art, Science and Society-Selected Papers of First World Chinese Fine Arts Education Seminar, edited by Education Research Center of Central Academy of Fine Arts, Hunan Fine Arts Publishing House, September 2009, page 106

[2] [England] E.H. Gombrich, Sense of Order-Psychological Study on Decorative Art, translated by Fan Jingzhong, etc. Hunan Science and Technology Press, first edition in January 2003, page 5

[3] [England] E.H. Gombrich, Art and Illusion-Psychological Research on Reappearance of Pictures, translated by Lin Xi, etc. Hunan Science and Technology Press, first edition in May 2002, page 107

[4] [Switzerland] Wolfflin, Principles of Art History, translated by Pan Yaochang, China Renmin University Press, page 271 